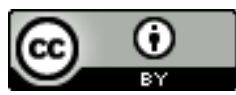

\title{
TECNOLOGIA DA FORMAÇÃO DOCENTE NO \\ CURRÍCULO DOS BLOGS SOBRE ALFABETIZAÇÃO
}

TEACHING TRAINING TECHNOLOGY IN THE

BLOG CURRICULUM ABOUT LITERACY

TECNOLOGÍA DE LA FORMACIÓN DOCENTE EN EL

CURRÍCULO DE LOS BLOGS SOBRE ALFABETIZACIÓN

\section{Gabriela Silveira Meireles ${ }^{1}$ \\ Marlucy Alves Paraíso ${ }^{2}$}

RESUMO: A presente pesquisa parte do entendimento de que o currículo é um artefato social e cultural que divulga saberes e modos de ser. O currículo dos blogs faz parte desse tipo de currículo que apresenta uma pedagogia cultural. A pesquisa que deu base para este artigo teve como objetivo investigar se há uma tecnologia da formação docente operando no currículo dos blogs nos blogs sobre alfabetização criados por professorasalfabetizadoras e por meio de que técnicas, tecnologias e estratégias esse currículo é posto em funcionamento. Para a realização da pesquisa, foram utilizadas duas abordagens metodológicas - a Netnografia para a realização da investigação em um espaço online; e a Análise do Discurso de inspiração foucaultiana para realizar as análises do material coletado. Concluímos, assim, que os blogs se constituem em um espaço que disputa com as Universidades e outras instituições para formar professoras-alfabetizadoras.

PALAVRAS-ChaVE: Tecnologia da formação docente. Currículo. Blogs sobre alfabetização.

ABSTRACT: The present research starts from the understanding that the curriculum is a social and cultural artifact that discloses knowledge and ways of being. The blog curriculum is part of this type of curriculum that presents a cultural pedagogy. The research that gave base to this article had the objective to investigate if there is a technology of the teacher formation operating in the curriculum of the blogs in the blogs on alphabetization created by literacy teachers and through which techniques, technologies and strategies this curriculum is put into operation . In order to carry out the research, two methodological approaches were used - the Netnography for conducting research in an online space; and the Discourse Analysis of Foucauldian inspiration to perform the analyzes of the collected material. We conclude, therefore, that blogs constitute a space that contests with universities and other institutions to train literacy teachers.

KEYWORDS: Teacher training technology. Curriculum. Blogs about literacy.

RESUMEN: La presente investigación parte del entendimiento de que el currículo es un artefacto social y cultural que divulga saber y modos de ser. El currículo de los blogs forma parte de ese tipo de currículo que presenta una pedagogía cultural. La investigación que dio base para este artículo tuvo como objetivo investigar si hay una tecnología de la formación docente operando en el currículo de los blogs en los blogs sobre alfabetización creados por profesoras-alfabetizadoras y por medio de qué técnicas, tecnologías y estrategias ese currículo es puesto en funcionamiento. Para la realización de la investigación, se utilizaron dos enfoques metodológicos - la Netnografía para la realización de la investigación en un espacio online; y el Análisis del Discurso de inspiración foucaultiana para realizar los análisis del material recolectado. Concluimos, así, que los blogs se constituyen en un espacio que disputa con las Universidades y otras instituciones para formar a profesoras alfabetizadoras.

Submetido em: 21/03/2018 - Aceito em: 11/05/2018 - Publicado em: 20/11/2018 
PALABRAS CLAVE: Tecnología de la formación docente. Plan de estúdios. Blogs sobre alfabetización.

\section{INTRODUÇÃO}

O currículo dos blogs investigados ${ }^{\mathrm{i}}$ é um "artefato cultural que ensina, educa e produz sujeitos” (PARAÍSO, 2010a, p. 11). Um currículo sempre se constrói e se mantém em meio a disputas, já que os conhecimentos que nele são divulgados estão sempre sujeitos à interpretação, a partir dos quais "os diferentes grupos tentam estabelecer a sua hegemonia" (SILVA, 2013, p. 134-135).

No que se refere ao currículo dos blogs investigados, trata-se de um artefato cultural que possui uma pedagogia posta em ação para formar professoras-alfabetizadoras por meio da troca de experiências, da sugestão de leituras, de atividades e da discussão sobre o que e como ensinar nessa etapa do Ensino Fundamental. Trata-se de um currículo que, por isso mesmo, disputa espaço com outros currículos de formação docente, como o das Universidades, constituindo-se em um espaço "alternativo" e/ou complementar a esse tipo de formação. Nele são prescritos, por professoras-alfabetizadoras, saberes "para a docente formar-se" (PARAÍSO, 2007, p. 94) e "modos de ser, estar e fazer considerados desejáveis" (PARAÍSO, 2007, p. 94) para as professoras-alfabetizadoras.

Com base na perspectiva adotada neste artigo, consideramos que a seleção do repertório daquilo que deve ser ensinado às docentes "tem sempre envolvimento com relações de poder" (PARAÍSO, 2007, p. 93) e com a produção de sujeitos. O poder é aqui entendido como "circulante" e "produtivo", uma vez que se constitui em relações de forças que incitam, suscitam, incentivam e fazem falar (FONSECA, 1995). Para que esse poder se exerça, é necessário, pois, colocar em circulação determinados saberes, já que as relações de poder somente se efetuam "conjuntamente com a produção de saberes a elas relacionados" (FONSECA, 1995, p. 34). O poder também está implicado na fabricação de sujeitos, que para Foucault (1993), é produzida por meio de duas tecnologias - "as tecnologias de dominação"ii e "as tecnologias do eu" iii.

Essas tecnologias possibilitam que os indivíduos "efetuem, por conta própria ou com a ajuda de outros, certo número de operações sobre seu corpo e sua alma, pensamentos, conduta ou qualquer forma de ser, obtendo, assim, uma transformação de si mesmos" (FOUCAULT, 1993, p. 207). As tecnologias são aqui entendidas como os meios que "têm sido inventados para governar o ser humano, para moldar ou orientar a conduta nas direções desejadas (ROSE, 2001b, p. 37). 
As relações entre tecnologias e técnicas podem ser analisadas pelas "intencionalidades e estratégias dentro das práticas, discursivas ou não, que supõe uma confrontação de ações com outras ações e de discursos com outros discursos" (FONSECA, 1995, p. 33). Assim, os discursos se utilizam das tecnologias e das técnicas para que um indivíduo possa "moldar e direcionar a conduta de si e dos outros" (PARAÍSO, 2006, p. 104). As tecnologias são sempre "montagens híbridas de saberes, instrumentos, pessoas, sistemas de julgamento, edifícios e espaços, orientados, no nível programático, por certos pressupostos e objetivos sobre os seres humanos" (ROSE, 2001a, p. 38). As técnicas, acionadas na tecnologia da formação docente e descritas neste artigo, são "os procedimentos e os exercícios que usamos sobre nós mesmos e que outros usam sobre nós nos processos de subjetivação" (PARAÍSO, 2007, p. 57).

A metodologia adotada nesta pesquisa utiliza-se de alguns elementos da Netnografia ${ }^{\text {iv }}$ para a "produção das informações" aqui analisadas. As análises das "informações produzidas" (MEYER; PARAÍSO, 2012, p. 14) foram realizadas com base em alguns elementos da Análise do Discurso de inspiração foucaultiana. Com isso, foi possível compreender os jogos discursivos que produzem saberes e práticas relacionados ao ensino, à aprendizagem, à escola, às professoras-alfabetizadoras, às/aos alunas/os, às atividades escolares e aos materiais de ensino-aprendizagem no currículo dos blogs sobre alfabetização criados por professoras-alfabetizadoras. Ela surge como possibilidade de analisar "como se instaura certo discurso, quais suas condições de emergência ou suas condições de produção" (FISCHER, 2001, p. 216). A intenção nesse tipo de análise é "multiplicar" também o sujeito, indagando sobre "o lugar de onde fala, o lugar específico no interior de uma dada instituição, a fonte do discurso daquele falante, e sobre a sua efetiva posição de sujeito, suas ações concretas, basicamente como sujeito incitador e produtor de saberes" (FISCHER, 2001, p. 208).

Os blogs sobre alfabetização investigados são analisados como um currículo que está envolvido com relações de poder, que governam condutas, que estruturam ações de si e dos outros. Um poder que "está espalhado por toda a rede social", um poder que "transforma-se" e que "não desaparece" (SILVA, 2013, p. 148-149). Para Silva (2013, p. 135), nenhum currículo pode ser entendido sem uma "análise das relações de poder". O poder "coloca em jogo relações entre indivíduos (ou entre grupos)" (FOUCAULT, 1995, p. 240). Por meio de relações de poder, é possível a produção de "ações que se induzem e se respondem umas às outras" (FOUCAULT, 1995, p. 240), produzindo práticas. A tecnologia e as técnicas que são sempre de poder são utilizadas para "fazer com que essas práticas sejam viabilizadas" (PARAÍSO, 2007, p. 176). São esses conceitos e essas relações que são importantes neste artigo para analisar a tecnologia da formação docente acionada nos blogs sobre alfabetização investigados. Apresentamos a seguir as duas técnicas que fazem a tecnologia da formação docente funcionar no currículo dos blogs investigados: a técnica da coletivização das informações e a técnica da valorização do saber-fazer. 


\section{A TÉCNICA DA COLETIVIZAÇÃO DAS INFORMAÇÕES FAZENDO OPERAR A TECNOLOGIA DA FORMAÇÃO DOCENTE NO CURRÍCULO DOS BLOGS SOBRE ALFABETIZAÇÃO}

O currículo dos blogs investigados apresenta uma lógica de "formação coletiva" na qual tanto quem escreve o blog quanto quem comenta participa de um movimento que faz a demanda por alguns assuntos relacionados à alfabetização ou materiais aumentar ou diminuir. Esse tipo de formação é viabilizado porque há, segundo Lévy (2015), uma "inteligência coletiva" circulando e sendo implementada em sociedades como a nossa, que se baseiam cada vez mais nas "tecnologias digitais da informação" (LÉVY, 2015, p. 29). Essa inteligência coletiva permite "compartilhar nossos conhecimentos e apontá-los uns para os outros" (LÉVY, 2015 p. 18). Ela pode ser entendida como "uma inteligência distribuída por toda parte", proporcionando "o enriquecimento mútuo das pessoas" (LÉVY, 2015, p. 29). Nesse sentido, uma das estratégias adotadas nos blogs investigados para fazer a tecnologia da formação docente funcionar é a disponibilização de grande quantidade de materiais para as professorasalfabetizadoras escolherem.

Fica evidente nos blogs investigados que há uma demanda das professoras-alfabetizadoras em acessá-los para copiar atividades, imprimi-las e distribuí-las aos/às alunos/as. Tal ação se evidencia pelo próprio conteúdo que costuma ser divulgado nos blogs analisados geralmente atividades prontas a serem xerografadas ou impressas - e até mesmo pela prevalência de atividades desse tipo em relação a outras mais criativas, artísticas ou inovadoras. As blogueiras que criam os blogs sabem disso e, por isso, disponibilizam inúmeras atividades em seus blogs. Tal ação mostra como a técnica da coletivização das informações é acionada pela tecnologia da formação para disponibilizar amplamente esses materiais.

De certo modo, nessa técnica, não importa muito quem criou o blog, nem se seu conteúdo é confiável. A oferta é dada pelas professoras que criam os blogs e as professoras leitoras copiam e/ou imprimem dos blogs tudo o que pode ser útil. Muitas vezes, não há interação direta entre as blogueiras e os/as visitantes do blog. Contudo, há uma rede de compartilhamento dessas atividades, o que faz com que a comunidade blogueira funcione como uma "troca" de materiais e saberes: "Ninguém sabe tudo, todos sabem alguma coisa" (LÉVY, 2015, p. 29).

Uma professora-blogueira divulga o que fez e outra professora divulga também o que fez, depois as professoras e/ou blogueiras copiam uma da outra e, em vez de uma atividade, terão duas, três, quatro, inúmeras atividades. A divulgação de atividades nos blogs é numerosa e nos permite levantar a hipótese de que essas professoras-blogueiras querem "suprir uma lacuna" deixada pelos cursos de formação superior no que tange a uma formação mais

\begin{tabular}{l|l|l|l|l|l|l|} 
(c) Rev. Educ. Perspec. & Viçosa, $M G$ & v.9 & n.2 & p.292-312 & maio/ago. 2018 & eISSN 2178-8359 \\
\hline
\end{tabular}


voltada para a "prática", espaço este que os blogs sobre alfabetização demonstram ocupar algumas vezes. A tecnologia da formação docente em funcionamento nos blogs investigados nos mostram que eles têm suas características próprias enquanto currículo e que as formas de aprendizagem neles postas em circulação são outras e diferentes daquelas enfatizadas, por exemplo, em um currículo Universitário.

As produções tanto no campo do currículo como no da formação docente fizeram críticas contundentes à perspectiva tecnicista que prevaleceu na década de 1970, no Brasil, e que concebia o/a professor/a apenas como "executor de tarefas" (AZEVEDO et al. 2013, p. 100) ou como um "desenvolvedor" de currículos pensados e elaborados por outros (SANTOS; PARAÍSO, 1996). O tema ou a palavra chave dessa abordagem curricular é exatamente "desenvolvimento", tendo em vista que cabia ao/à professor/a desenvolver currículos pensados, planejados e definidos por outros (MOREIRA, 1990; SANTOS; PARAÍSO, 1996; SILVA, 2013). Embora haja no currículo dos blogs investigados, críticas ao processo de "homogeneização no ensino", também há claramente neles uma prática bastante comum de divulgar inúmeras atividades prontas para professoras-alfabetizadoras imprimirem e desenvolverem com as crianças. Nesse aspecto o currículo dos blogs se aproxima da perspectiva tecnicista da educação, já que tem uma grande preocupação em divulgar exercícios prontos para serem desenvolvidos por outras professoras-alfabetizadoras.

Os blogs investigados compõem um currículo de formação docente que atua para construir um repertório permanente e acessível de materiais e atividades sobre alfabetização à todos/as que puderem acessar a internet. Nesse sentido, qualquer professor/a interessado/a em um dado assunto sobre alfabetização pode ter acesso a esses blogs e neles aprender. Se as informações e os materiais sobre alfabetização passam a estar disponíveis nesses blogs, as professoras podem acessar informações, textos e atividades para suas aulas em suas próprias casas ou mesmo nas escolas. Basta ter um computador, tablet ou smartphone e acesso à internet. Isso pode estar evidenciando a existência de uma prática bastante nova que merece investigação. Afinal, como lembra Michel Serres (2013, p. 26), "o acesso ao saber se abriu”, está "por todo lugar"; eles circulam pela internet e estão acessíveis a muita gente.

De fato, há nos blogs sobre alfabetização investigados uma quantidade enorme de informações disponíveis por meio de textos acadêmicos, exercícios, atividades, relatos, livros, depoimentos. Além disso, o fato de existir "um buscador on-line" - Google - que redireciona as nossas buscas a alguns desses blogs faz com que essas informações sejam acessadas facilmente pelas professoras-alfabetizadoras. Basta digitar o assunto de interesse relacionado à alfabetização, que seremos redirecionados para um desses blogs ou para outros sites. 
Em levantamento realizado nos links intitulados "Alfabetização" disponíveis nos blogs investigados, foi possível verificarmos que o material mais divulgado é o das "Atividades de alfabetização" (em 88 posts). Esse investimento tanto pode ter relação com o fato de que a disponibilização desse tipo de material na internet tem um baixo custo, o que facilita o seu acesso, quanto pode ter relação com uma necessidade das blogueiras em produzir materiais que elas consideram mais adequados para seus/suas alunos/as, do que os encontrados em livros didáticos, por exemplo. Todavia, o que percebemos é que todos os 88 posts divulgam atividades prontas para serem fotocopiadas pelas professoras-alfabetizadoras visitantes de cada um desses blogs e já, em seguida, usarem com seus/suas alunos/as. Nesse caso, é possível arriscarmo-nos a dizer que tecnologia da formação docente acionada nos blogs sobre alfabetização vem anunciar possíveis lacunas sentidas pelas professoras-alfabetizadoras em seus processos formativos.

Outro material bastante presente nos blogs educativos sobre alfabetização criados por professoras-alfabetizadoras e que faz funcionar a tecnologia da formação docente refere-se aos Jogos Pedagógicos ou Jogos para Alfabetizar (em 43 posts). A professora Adri comenta no post intitulado "Alfabetização - Jogos Pedagógicos", que "O jogo pode ser extremamente interessante como instrumento pedagógico, pois incentiva a interação e desperta o interesse pelo tema estudado, além de fomentar o prazer e a curiosidade".

Além de serem materiais pedagógicos caros ao currículo dos blogs sobre alfabetização investigados, os jogos para alfabetizar são também recomendados: 1) Na Plataforma do Letramento $^{\text {vi }}$; 2) No Pacto Nacional pela Alfabetização na Idade Certa (PNAIC) ${ }^{\text {vii; }} 3$ ) Nos "Cadernos de Alfabetização 2015"; 4) No item "A organização do trabalho escolar e os recursos didáticos na alfabetização"; 5) No item intitulado "Diversos jogos no Ciclo de Alfabetização: usos e funções"; 6) Nos "Cadernos de Educação Matemática" (em dois itens intitulados "Jogos na Alfabetização Matemática" e "Encarte dos Jogos na Alfabetização Matemática"); 7) No Portal do Professor ${ }^{\text {viii }}$ (nas aulas de 1 a 3, intituladas como "Compartilhando conhecimentos sobre brincadeiras e jogos").

Os Jogos e/ou as Brincadeiras também são uma preocupação na formação da professoraalfabetizadora. Esse movimento pode ser percebido nos textos intitulados "Por que trabalhar com jogos?", "Por que jogos na alfabetização?" e "Os jogos desta coletânea: o que queremos com eles?" divulgados em um Manual de Jogos para a Alfabetização em um dos blogs investigados ${ }^{\mathrm{ix}}$. Ambos enfatizam "o papel da atividade lúdica na Educação" e o "direito da criança brincar” (FORTUNA; VIEIRA, 2005, p. 81).

Cabe registrarmos que, embora haja um investimento no trabalho com os jogos, com uma maior flexibilidade na elaboração das informações e conceitos pelos/as alunos/as - um tipo de atividade que está mais vinculada à perspectiva crítica da educação (PIAGET, 1975;

v.9

n.2

p.292-312


ELKONIN, 1998; BROUGÈRE, 1998; LIMA, 2008) -, ainda se faz muito presente nos blogs investigados uma visão bastante "tradicional" de alfabetização, que costuma enfatizar a codificação e a decodificação do sistema de escrita (SOARES, 2004), começando, geralmente, com o aprendizado das letras, por exemplo.

No levantamento já citado, os posts sobre o "Alfabeto" foram os terceiros mais citados (em 39 posts). Neles, encontram-se vários tipos e modelos de "Alfabetos", a saber: Alfabeto Musical, Alfabeto da Turma da Mônica, Alfabeto dos Animais, Alfabeto Redondo Ilustrado, Alfabeto em Inglês para Imprimir, Alfabeto Letra Maiúscula Pontilhado A-Z, Alfabeto Letras Minúsculas Pontilhado A-Z, Alfabeto para Imprimir e Pintar, etc. Eles são apresentados nos blogs como material para se colocar na parede das salas de alfabetização.

A apresentação desses "modelos" de alfabeto, já prontos para imprimir, é algo que geralmente não se encontra no currículo da formação universitária, já que muitas críticas foram feitas aos métodos tradicionais de alfabetização (PEREIRA et al. 2013; CALDEIRA, 2016). No entanto, Magda Soares (2003, p. 19) afirma a necessidade de uma "reinvenção da alfabetização", para "recuperar sua especificidade", ou seja, para lembrar que "ninguém aprende a ler e a escrever se não aprender relações entre fonemas e grafemas - para codificar e para decodificar" (SOARES, 2003, p. 17). Nesse caso, o ensino das letras, seus sons e suas formas deixa de ser menosprezado, o que não significa que o trabalho reproducionista (que expõe o alfabeto na parede) seja suficiente para o aprendizado complexo do sistema alfabético. Para que isso ocorra, como explica Morais (2006, p. 5), é preciso "estimular a exploração de certas propriedades do sistema alfabético (ordem, identidade, quantidade das letras, etc.)".

A disponibilização desse tipo de material pronto e de fácil reprodução nos blogs sobre alfabetização é uma das estratégias acionadas pela técnica da coletivização das informações, de modo a garantir que as professoras-alfabetizadoras tenham um repertório variado (vários modelos de alfabeto) e possam escolher qual deles usar. Desse modo, se antes prevalecia o uso de um método concretizado em uma "cartilha ${ }^{\mathrm{x}}$, acompanhado de um manual do professor (da alfabetizadora) dizendo detalhadamente o que ela deveria fazer" (SOARES, 2003, p. 17), hoje os blogs sobre alfabetização criados por professoras-alfabetizadoras usam como estratégia a disponibilização de grande quantidade de materiais e/ou de materiais pedagógicos possíveis para que a própria professora-alfabetizadora faça suas escolhas do que utilizar e de como utilizar. Se antes "a verdade era exclusivamente o que dizia a cartilha" (SOARES, 2003, p. 17), hoje temos teorias que explicam como se aprende ${ }^{\mathrm{xi}}$, cabendo a cada professora a escolha de que método adotar.

A divulgação de cartilhas (e também livros didáticos, apostilas e cadernos pedagógicos voltados especificamente para a alfabetização) é bastante comum nos blogs sobre

v.9

n. 2

p.292-312


alfabetização investigados. A professora Adri disponibiliza on-line a "Apostila Ler e Escrever", que traz atividades para o $1^{\circ}$ ano e um Livro Didático de Alfabetização (Livro do Professor). Essa professora disponibiliza também o livro didático intitulado "Palavra em Contexto", aprovado pelo Ministério da Educação (MEC) e financiado pelo Fundo Nacional de Desenvolvimento da Educação (FNDE), que distribui livros didáticos nas escolas. Do mesmo modo, a professora Juciene Bertoldo disponibiliza os "Cadernos Pedagógicos do Rio de Janeiro 2014", os "Cadernos Pedagógicos do Paraná" e um "Guia da Alfabetização em Família". Esse último documento é destinado às mães e aos pais dos/as alunos/as, trazendo algumas dicas sobre como eles/as devem proceder para ajudar na alfabetização de seus/suas filhos/as.

A tecnologia da formação docente é acionada nos blogs investigados, portanto, divulgando uma grande quantidade de cartilhas e materiais prontos para professoras-alfabetizadoras e também para outras pessoas interessadas pela alfabetização, como mães de alunos. Paraíso (2010b) mostra que é comum a responsabilização da mãe pelo cuidado e pela escolarização dos filhos. Nessa lógica, é a mãe que busca adquirir esses materiais para anteciparem o processo de alfabetização em casa antes mesmo do ingresso das crianças na escola, como mostra a visitante Ana Paula no blog CEFAPRO de Pontes e Lacerda: "queria muito um livro desse para alfabetizar minhas meninas em casa, para ficar melhor quando for na escola [...]".

Ao divulgar antigos livros e cartilhas de alfabetização, o currículo dos blogs investigados vai na contramão das recomendações dos/as teóricos/as, dos documentos oficiais e também daquilo que as Editoras ${ }^{\text {xii }}$ divulgam hoje sobre a alfabetização. A técnica da coletivização das informações e a multiplicação dos materiais são importantes para a tecnologia da formação docente funcionar. Contudo, opera de modo conflitante, por exemplo, com os Parâmetros Curriculares Nacionais (PCNs), que entendem que se deve evitar o uso de textos que têm como única finalidade ensinar a ler e a escrever, já que "sequer podem ser considerados textos, pois não passam de simples agregados de frases" (BRASIL, 1997, p. 29). Contudo, a tecnologia da formação docente aciona aqui lembranças das professoras-alfabetizadoras que foram alfabetizadas ou que tiveram seus/suas alunos/as ou seus/as filhos/as alfabetizados/as com esses livros e/ou cartilhas. Assim, a tecnologia da formação docente aciona emoções e lembranças e opera retomando ou divulgando materiais que, de algum modo, possam tocar mães e professoras-alfabetizadoras que, provavelmente, não conhecem as críticas a esses materiais.

No que diz respeito ao currículo oficial ${ }^{\text {xiii }}$, ou seja, aos documentos em geral produzidos pelas instâncias do Governo (municipal, estadual e federal), é possível afirmar que os PCNs e o Referencial Curricular Nacional para a Educação Infantil (RCNEI) foram os únicos documentos curriculares divulgados nos blogs investigados. São poucos os blogs que divulgam posts ou links sobre outra política curricular ${ }^{\text {xiv }}$. Apenas 3 blogs: um sobre os PCNs, 
denominado "PCN Ação Alfabetização" e outros dois sobre o Referencial Curricular Nacional para a Educação Infantil. No que tange aos PCNs, por exemplo, uma das críticas feitas por Moreira (1996, p. 15) é que o documento tende a "sacralizar as disciplinas acadêmicas tradicionais, vistas como as únicas possíveis e desejáveis, ao invés de resultantes de escolhas de determinados grupos".

Diante disso, é possível afirmarmos que o currículo oficial é incorporado pelos blogs investigados, que consideram esses documentos úteis para que as professoras-alfabetizadoras estejam capacitadas a ensinar o que as avaliações cobram. Há, pois, uma rede de compartilhamento de links que disponibiliza modelos de avaliação para as professorasalfabetizadoras, pressupondo que elas precisam daqueles materiais. Exige-se hoje do/a professor/a uma postura de "aprendiz", de modo que ele/a esteja aberto à mudança, ao desenvolvimento de novos métodos de ensino-aprendizagem, sendo flexível, inovador/a, colaborador/a, criador/a e atento/a às necessidades dos alunos, pais e comunidade (LEITE; ORVALHO, 1995, p. 30-31). Assim, os blogs se constituem em uma comunidade de aprendizagem que compartilha certas competências específicas da área da alfabetização, sendo esse um dos principais motivos pelos quais eles também são criados, escritos e acessados pelas professoras-alfabetizadoras.

O currículo dos blogs sobre alfabetização aciona a estratégia da disponibilização de grande quantidade de materiais em relação à avaliação para que as professoras-alfabetizadoras possam utilizá-lo. Com isso, os blogs acabam se tornando um espaço de formação que ora vai na direção das políticas educacionais, ora vai na contramão dessas políticas, indicando que o currículo dos blogs investigados se constitui em um currículo de formação de alfabetizadoras que possui seus interesses e que não se compromete com nenhuma tendência específica das diferentes abordagens curriculares. Assim, mostramos nesse item que a tecnologia da formação docente é acionada por meio da técnica da disponibilização de grande quantidade de materiais, sendo comum o uso de materiais distintos sem a preocupação com críticas que já foram feitas ao uso acrítico desses materiais e sem divulgar qualquer material que faça críticas às políticas educacionais como os PCNs ou às avaliações nacionais. Isso mostra que, no currículo investigado, não há muito espaço para um/a professor/a-reflexivo. Ao contrário, a lógica afirmada no currículo dos blogs pesquisados é muito mais a da "reprodução de materiais", embora haja exceções.

A seguir, analisaremos a técnica da valorização do saber-fazer que também é acionada no currículo dos blogs sobre alfabetização investigados e que faz a tecnologia da formação docente funcionar. 


\section{A TÉCNICA DA VALORIZAÇÃO DO SABER-FAZER FAZENDO OPERAR A TECNOLOGIA DA FORMAÇÃO DOCENTE NO CURRÍCULO DOS BLOGS SOBRE ALFABETIZAÇÃO}

Ao colocar como alvo de seus saberes e poderes as professoras-alfabetizadoras, o currículo dos blogs investigados torna-se uma "máquina de ensinar" (GIROUX, 1995, p. 51) acionada para fazer as professoras-alfabetizadoras se identificarem com esse currículo. Trata-se de uma máquina de ensinar que quer fazer com que as professoras reproduzam os materiais ali divulgados, elogiem os blogs e se vinculem umas às outras, constituindo uma rede de professoras-alfabetizadoras-blogueiras que não medem sacrifícios para se ajudarem na tarefa de alfabetizar. Nesse processo, as professoras-alfabetizadoras se conectam, trocam experiências e se formam.

A experiência em sala de aula contada nos blogs por meio da disponibilização do número de anos de docência ou de alguma atividade considerada valorizada (tais como: "Eu leciono a mais de dez anos"xv; "Já trabalhei em escola particular, escola de idiomas e inclusive já tive minha própria escola de idiomas"xvi; "Trabalho há vinte anos com crianças de 6 a 13 anos em escolas públicas"xvii; "Atuo como professora de alfabetização desde 2002"xviii; "Blogger desde fevereiro de 2008"xix; trata-se da técnica da valorização do saber-fazer que é acionada para fazer funcionar a tecnologia da formação docente nos blogs investigados. É como se dissessem: eu faço, sei fazer e posso ensinar.

Além disso, cursos realizados pelas blogueiras (suas qualificações) são divulgados, tais como: Sou "Orientadora de Estudos do PNAIC"; "Trabalho com assessoria [...], desenvolvendo cursos, assessorando escolas e ministrando oficinas"xx; Desejo "contribuir mais e mais na formação dos professores",xxi , Sou "pós-graduada em Formação de Professores"xxii. As qualificações são usadas para mostrar que essas professoras são autorizadas a ensinar outras professoras-alfabetizadoras, a formar outras professoras. Além de contribuir para a formação das professoras-alfabetizadoras, algumas blogueiras relatam seus desejos de "elaborar um material próprio" e de atuar "montando, elaborando, criando, pesquisando para os professores"xxiii. Assim, nos blogs investigados, a tecnologia da formação docente apresenta as próprias blogueiras como "profissionais competentes e apaixonados pela educação"xxiv .

Ao expor as experiências das blogueiras com a alfabetização, focadas, na maioria das vezes, na divulgação de materiais prontos e no compartilhamento de possíveis formas de intervenção em sala de aula, os blogs acionam a tecnologia da formação docente para mostrar esses materiais e essas experiências como algo a ser imitado, uma estratégia bastante usada também pela mídia educativa brasileira investigada por Paraíso (2007). A experiência valorizada nos blogs advém de um "saber-fazer" que atua como uma técnica que faz

\begin{tabular}{l|l|l|l|l|l|l|} 
(c) Rev. Educ. Perspec. & Viçosa, $M G$ & v.9 & n.2 & p.292-312 & maio/ago. 2018 & eISSN 2178-8359 \\
\hline
\end{tabular}


funcionar a tecnologia da formação docente. A professora Janína Spolidorio, por exemplo, cria a personagem "Fada Alfabeta" - indicada como uma grande heroína da alfabetização como alguém que assume "uma grande responsabilidade!". Ela tem uma página no facebook (https://www.facebook.com/fadaalfabeta/) na qual vai tratar apenas de alfabetização. Afinal de contas, ela é "especialista no assunto!". Colocar-se como heroína é uma das maneiras de afirmar que a fada, a própria professora-blogueira desse blog, tem como difícil tarefa a de alfabetizar as crianças. Ao mesmo tempo, ao apresentar-se como "especialista no assunto", a fada-professora indica algo que ela não apenas sabe fazer, como sabe fazer muito bem, que é alfabetizar. A técnica da valorização do saber-fazer é acionada aqui para ensinar que "quem sabe fazer pode ensinar, pode formar"!

Um link intitulado "Trabalho com as hipóteses dos alunos" mostra como as professoras assumem essa tarefa de alfabetizar. Elas sintetizam e tornam um conhecimento teórico bem acessível às colegas professoras, explicando, dando exemplos, traduzindo. Além disso, os blogs propõem modos de fazer adequados para cada uma das fases de construção da escrita. Abaixo, reproduzimos um quadro publicado em um blog para ensinar as características de cada uma das hipóteses de escrita, ao mesmo tempo em que sugerem as intervenções que devem ser feitas por cada professora para alfabetizar seus/suas alunos/as:

Quadro 1. Hipóteses de escrita dos/as alunos/as.

\begin{tabular}{|c|c|c|c|}
\hline ALFABÉTICA & $\begin{array}{c}\text { SILABICA } \\
\text { ALFABETICA }\end{array}$ & SILABICA & PRÉ SILÁBICA \\
\hline $\begin{array}{l}\text { Caracteristicas: } \\
\text { 1. Escreve compondo } \\
\text { silabas foneticamente } \\
\text { corretas; } \\
\text { 2. Desconsideram a } \\
\text { segmentação entre } \\
\text { palavras; } \\
\text { 3. Hipercorreção: } \\
\text { exagera no uso de } \\
\text { acentos e pontuação. }\end{array}$ & $\begin{array}{l}\text { Caracteristicas: } \\
\text { 1. Fase de transição - } \\
\text { silábico e o alfabético. } \\
\text { 2. Ora compõe silabas, } \\
\text { ora não compõe na } \\
\text { mesma palavra. } \\
\text { 3. Faz maior uso de } \\
\text { consoante. } \\
\text { 4. Acredita que } \\
\text { algumas consoantes se } \\
\text { bastam para a } \\
\text { composição da sílaba. } \\
\text { Ex: B = BE. }\end{array}$ & $\begin{array}{l}\text { Características: } \\
\text { 1. Percebe a relação entre } \\
\text { a oralidade e a escrita. } \\
\text { 2. Usa uma letra para } \\
\text { cada som. } \\
\text { 3. Pode ou não fazer uso } \\
\text { de valor sonoro } \\
\text { 4. Determina minimo de } \\
\text { letras. }\end{array}$ & $\begin{array}{l}\text { Características: } \\
\text { 1. Utilizam números, letras e } \\
\text { psedo-letras. } \\
\text { 2. O critério de qualidade é forte. } \\
\text { 3. Não compreendem que a escrita } \\
\text { é a representação da fala. } \\
\text { 4. Realismo nominal (quanto maior } \\
\text { o objeto representado, maior o } \\
\text { número de caracteres) Ex: A } \\
\text { formiga é pequena por isso } \\
\text { escrevem com menos letras, } \\
\text { enquanto que o boi é grande então } \\
\text { eles escrevem com mais letras. }\end{array}$ \\
\hline $\begin{array}{l}\text { Intervencões: } \\
\text { 1. Consultar } \\
\text { dicionário; } \\
\text { 2. Revisão de textos; } \\
\text { 3. Quadro de } \\
\text { regularidades; } \\
\text { 4. Forca; } \\
\text { 5.Segmentar pequenos } \\
\text { textos (parlendas, } \\
\text { quadrinhas etc). } \\
\text { 6.Pintar lacuna entre } \\
\text { palauras em pequenos } \\
\text { textos (segmentação). }\end{array}$ & $\begin{array}{c}\text { Intervenções: } \\
\text { 1. Cruzadinhas; } \\
\text { 2. Forca; } \\
\text { 3. Texto lacunado; } \\
\text { 4. Pedir para a criança } \\
\text { ler o que escreveu; } \\
\text { 5. Ler para a criança o } \\
\text { que ela escreveu do } \\
\text { modo que ela } \\
\text { escreveu. }\end{array}$ & $\begin{array}{c}\text { Intervencões: } \\
\text { Trabalhar com nomes dos } \\
\text { alunos. } \\
\text { Textos de memória } \\
\text { (parlenda, cantigas, listas } \\
\text { etc). } \\
\text { Cruzadinhas e textos } \\
\text { lacunados para perceber } \\
\text { o número de letras das } \\
\text { palavras. } \\
\text { Atividades para contar as } \\
\text { letras e as silabas das } \\
\text { palavras. } \\
\text { Atividade para alterar } \\
\text { vogais e manter as } \\
\text { consoantes. Ex: BOLA- } \\
\text { BOLO -BELA }\end{array}$ & $\begin{array}{c}\text { Intervençòes: } \\
\text { 1. Trabalhar com o o nome próprio } \\
\text { e dos outros } \\
\text { 2. Leitura de textos que saibam de } \\
\text { memória pelo professor e pelo } \\
\text { aluno (parlendas, cantigas, trava- } \\
\text { linguas etc) } \\
\text { 3. Oferecer lista de palavras com } \\
\text { lacunas/ figuras } \\
\text { 4. Cruzadinhas com banco de } \\
\text { palavras e/ou com imagens }\end{array}$ \\
\hline
\end{tabular}

Fonte: Blog Minha Paixão: Alfabetização. Disponível em: <http://diariodaprofaglauce.blogspot.com.br/>. Acesso em: 12 maio 2015. 
Mesmo quando os blogs explicam um tema - como nesse caso, em que se explicam as diferentes hipóteses de construção da escrita para a Psicogênese da Língua Escrita -, o saberfazer ganha destaque. Por meio do que o blog chama de "intervenções", a tecnologia da formação docente é acionada no currículo dos blogs investigados para formar outras professoras-alfabetizadoras. Eles acionam a técnica do saber-fazer também quando as professoras-alfabetizadoras precisam definir o método a ser utilizado. Prescreve-se aí como se deve alfabetizar.

Sobre "como faz" e "como se pode fazer", uma professora-alfabetizadora-blogueira diz: "Não gosto de nomear métodos. No início da Alfabetização $\left(1^{\circ}\right.$ ano $)$ costumo trabalhar partindo da Palavra, mas uma palavra contextualizada, sempre partindo do texto que geralmente pode ser uma música ou poesia"xxv. Uma outra faz a pergunta "Como alfabetizar?" e, em seguida, ensina o que considera que deve ser feito pelas professoras-alfabetizadoras: "Como alfabetizar"? Criando um ambiente alfabetizador; Oferecer atividades que favoreçam a alfabetização; Trabalhar com Crachás"xxvi. Uma outra dá explicações do método alfabético, ensina sobre as críticas feitas a ele e explica porque ele ainda é usado e onde é usado:

O método alfabético, apesar de não ser o indicado pelos Parâmetros Curriculares Nacionais, ainda é muito utilizado em diversas cidades do interior do Nordeste e Norte do país, já que é mais simples de ser aplicado por professores leigos, através da repetição das Cartas de $\mathrm{ABC}$, e na alfabetização doméstica ${ }^{\text {xxvii }}$.

O currículo dos blogs investigados ao acionar a tecnologia da formação docente coloca foco nos métodos para se alfabetizar. O interesse das professoras-alfabetizadoras por essa temática pode ser evidenciado pela quantidade de comentários relacionados ao post "Métodos de alfabetização: quais são e como funciona?"xxviii - 93 comentários. Dentre eles, muitos expressam opiniões sobre o melhor método a ser adotado; algumas se assumem como "professora tradicional", defendendo os antigos métodos para se alfabetizar; algumas defendem o Construtivismo, enquanto outras o consideram uma "proposta falida". Há aí um recorrente ensinamento sobre eles. É possível notarmos nos dois primeiros depoimentos que, ainda que os blogs não revelem "um método" por elas adotado, fala-se em modos, formas, procedimentos para alfabetizar. Soares (2016, p. 50) explica que método é o "conjunto de procedimentos que, com base em teorias e princípios linguísticos e psicológicos, orientam essa [a] aprendizagem".

Esses depoimentos mostram que há um conflito entre o que as professoras-alfabetizadoras fazem e ensinam e aquilo que é prescrito em documentos oficiais como os PCNs, que não recomendam o uso do método alfabético ou fônico. Ao ensinar sobre o método fônico, o blog mostra que um órgão francês e outro norte-americano - Observatório Nacional da Leitura da França e o Painel Nacional de Leitura dos EUA - afirmam "sua clara superioridade" em relação a outros métodos. Nesse caso, as professoras-blogueiras fazem suas escolhas do 
método de alfabetização e ensinam sobre sua superioridade, fazendo alusão à órgãos que podem ter um efeito de "autoridade" para outras professoras-alfabetizadoras.

Para ensinar, a técnica do saber-fazer é acionada porque ela dá autoridade também a quem está ensinando. Para Magda Soares (2016, p. 333), o que menos importa é a escolha de um ou mais métodos para alfabetizar, mas "alfabetizar com método", o que significa que as práticas pedagógicas devem ser construídas "por aqueles/as que alfabetizam compreendendo os processos cognitivos e linguísticos do processo de alfabetização".

A técnica do saber-fazer é acionada, ainda, por meio da estratégia do reconhecimento de outras professoras pelo trabalho realizado nesses blogs, o que ocorre tanto por meio de comentários quanto por meio do oferecimento de selinhos aos blogs (Figura 1). O reconhecimento observado nos blogs pode ser entendido ora como um reconhecimento daquilo que ele propõe em termos de informações, atividades, imagens, jogos, músicas, etc., ora como um reconhecimento dele ou da blogueira: "Nossa, seu blog é muito legal... algumas destas postagens carreguei comigo ok?”; "Muito boas essas atividades, parabéns!!!”; “São sugestões de atividades muito interessantes. Gostei".

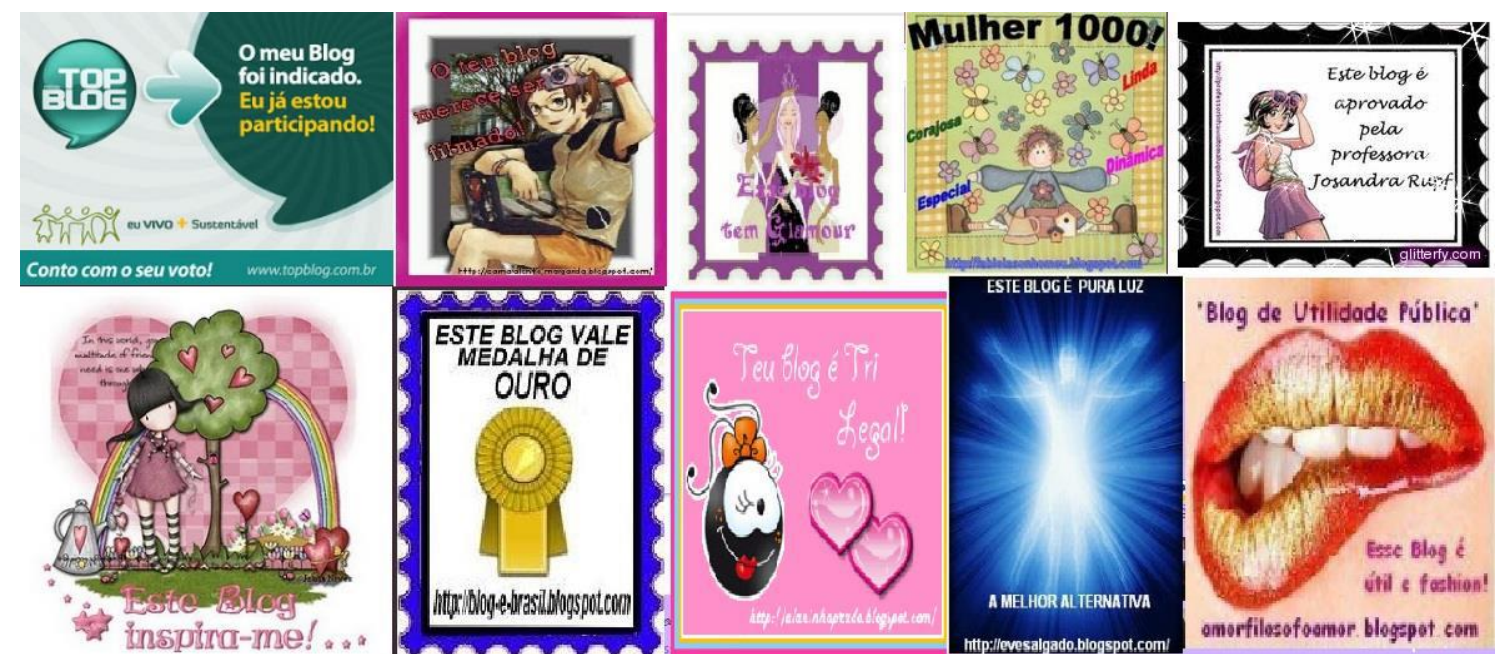

Figura 1. Exemplos de "selinhos" oferecidos nos blogs.

Fonte: Blogs variados dentre os investigados.

Ao afirmar que um dado blog "é muito legal", ao ponto de a comentarista querer "carregar" as atividades ali divulgadas com ela, o elogio às atividades disponibilizadas no blog - "Muito boas essas atividades, parabéns!!!" -, bem como a constatação de que são "sugestões de atividades muito interessantes", anunciam que aquilo que o currículo dos blogs está ensinando está recebendo a aprovação das professoras-alfabetizadoras-blogueiras-visitantes desses blogs, que não somente são formadas pelo que está ali divulgado, mas também passam a incorporar em suas práticas pedagógicas as atividades divulgadas. Os selinhos, assim como 
os comentários, surgem como estratégias de reconhecimento de outras professoras pelo trabalho realizado. Junto da técnica da valorização do saber-fazer, a "estratégia de reconhecimento" faz a tecnologia da formação docente funcionar ao mostrar que as professoras-blogueiras não apresentam vínculo com nenhum órgão oficial (Secretarias de Educação, MEC, etc.) nem necessitam da aprovação oficial (de avaliações oficiais, por exemplo).

Os selinhos mostram que o reconhecimento desses blogs e dos trabalhos neles divulgados, bem como das blogueiras, é feito por blogueiros/as visitantes, que se formam com eles, usam o que é neles divulgado e os avaliam. Muitas vezes, a avaliação é feita em forma de reconhecimento: "Top Blog. O meu blog foi indicado"; "Este blog merece ser filmado"; "Este blog tem glamour". Outras vezes a avaliação é feita por meio do registro, da aprovação ou elogio do blog: "Este blog é aprovado pela professora Josandra Rupf"; "Este blog vale medalha de outro"; "Este blog é tri legal"; "Este blog é pura luz. A melhor alternativa"; "Blog de utilidade pública. Esse blog é útil e fashion". Outras vezes, ainda, a avaliação é feita e há registro dos efeitos dela nas professoras-alfabetizadoras-blogueiras-visitantes: "Este Blog inspira-me". Por fim, há também a exaltação da própria blogueira: "Mulher mil! Corajosa, Linda, Especial, Dinâmica". É assim que a "estratégia de reconhecimento" é usada para fazer a tecnologia da formação docente funcionar nos blogs sobre alfabetização de professorasalfabetizadoras. As professoras-blogueiras têm no próprio blog um retorno dos efeitos daquilo que divulgam, disponibilizam, ensinam. O currículo dos blogs investigados convoca as professoras-alfabetizadoras-blogueiras a se posicionarem em relação à escolha/definição dos métodos de ensino que adotarão.

A discussão dos métodos também é feita por especialistas sobre alfabetização (FRADE, 2005; MORTATTI, 2006; CARVALHO, 2010), mas de modo diferente. Se para os/as especialistas os saberes sobre os métodos encaminham para um debate crítico que tende a eliminar os métodos mais tradicionais ${ }^{\text {xxix }}$, no currículo dos blogs os métodos aparecem de forma articulada ao objetivo de cada atividade realizada. O fato é que os "métodos de alfabetização têm sido sempre uma questão porque derivam de concepções diferentes sobre o objeto da alfabetização, isto é, sobre o que se ensina" (SOARES, 2016, p. 31-32, grifo do original). A autora afirma que "na grande maioria das escolas", a questão que se coloca é "a dúvida sobre o método a ser adotado, entre as várias opções existentes” (SOARES, 2012, p. 87). O currículo dos blogs investigados mostra que, de fato, essa é uma grande preocupação das professoras-alfabetizadoras-blogueiras. Por isso, elas explicam, ensinam, posicionam-se e convocam as professoras-alfabetizadoras a se posicionarem também.

Outro aspecto a ser destacado é que a técnica da valorização do saber-fazer da professoraalfabetizadora acionada pela tecnologia da formação docente costuma ser usada para divulgar um tipo de professora que "sabe o que faz", que "sabe escolher o método mais adequado" a

v.9

n. 2


cada turma e aluno/a, que sabe como alfabetizar e que, por isso, tem autoridade para ensinar, prescrever modos de proceder, formar outras colegas professoras-alfabetizadoras. Há, inclusive, uma defesa de que se misturem métodos e atividades, tradicional e Construtivista, por exemplo. Isso fica evidente em comentários como este feito por uma Anônima: "Acredito que um educador alfabetizador, competente e comprometido estará sempre em busca de um método eficaz e condizente com a realidade de seus alunos".

O que parece estar em jogo no saber alfabetizar aqui não é apenas o fato de ter tido uma boa formação universitária, mas também as experiências divulgadas e demonstradas em cada um dos blogs investigados, por meio das estratégias por elas utilizadas - a da disponibilização de grande quantidade de materiais e a da definição do método para se alfabetizar. Ambas as estratégias se articulam com técnicas nesse currículo - a da coletivização das informações e a da valorização do saber-fazer - e fazem com que a tecnologia da formação docente funcione no currículo dos blogs educativos sobre alfabetização investigados, divulgando experiências, disponibilizando saberes, prescrevendo intervenções, ensinando sobre métodos, convocando as professoras-alfabetizadoras-blogueiras a se formarem, aprenderem e a se posicionarem, avaliando o que esse currículo lhes oportuniza.

A tecnologia de formação docente em funcionamento nos blogs investigados conta com o fato de ser um currículo "em rede" e, por isso, tem maior facilidade de divulgar saberes, distribuir informações e disponibilizar materiais. Inseridas como estamos em uma sociedade que Serres (2000) chama de "sociedade pedagógica", que se caracteriza pela "passagem de um espaço de concentração para um espaço de distribuição" (SERRES, 2000, p. 133), essa tecnologia da formação docente funciona exatamente distribuindo, para quem puder e desejar acessar informações, experiências, opiniões, atividades, avaliações e saberes relativos à alfabetização, filtrados, selecionados e disponibilizados por professoras-alfabetizadorasblogueiras. Por meio da internet, se faz possível que "as pessoas compartilhem links com rapidez e eficiência" (JENKINS; FORD; GREEN, 2014, p. 35), com "múltiplas maneiras de circulação de conteúdo ${ }^{\mathrm{xxx}}$ hoje, de cima para baixo e de baixo para cima” (JENKINS; FORD; GREEN, 2014, p. 23).

\section{CONCLUINDO...}

A tecnologia da formação docente, acionada nos blogs investigados, faz circular um currículo que é híbrido, que gosta de "mistura", de atividades, que não afirma uma única tendência ou teoria pedagógica e que não apresenta um consenso sobre os modos de ensinar. O currículo dos blogs sobre alfabetização investigados se apresenta, assim, como aquele que tanto "joga" com o tradicional (disponibilizando atividades de cópia, reprodução de cartilhas, exercícios a serem impressos, replicados e aplicados por qualquer professora-alfabetizadora de qualquer 
região do país), como busca realizar tarefas que consideram mais inovadoras e condizentes com a necessidade dos alunos e com o contexto em que vivem.

A tecnologia da formação docente em funcionamento no currículo dos blogs investigados conta, para sua efetivação, com as mais diferentes temáticas sobre a alfabetização e com a liberdade para comunicar ou interagir com professoras-alfabetizadoras que estão passando pela mesma situação. Como um espaço de "formação alternativa" (LÉVY, 1999, p. 176), os blogs investigados atribuem grande valor à experiência profissional, à "aprendizagem coletiva" (LÉVY, 1999, p. 160) e à "pedagogia cooperativa” (LÉVY, 1999, p. 183), dando um lugar à experiência dessas docentes alfabetizadoras, mas também mostrando que, quando o/a professor/a se coloca nesse lugar de "professor aprendiz", ele/a passa também a se beneficiar desse processo ao aprender com os seus pares.

Trata-se de um currículo que concorre com outros currículos, como o das Universidades, mas que não o substitui. Trata-se de um espaço "alternativo" e/ou complementar a esse tipo de formação. Assim, a tecnologia da formação docente acionada nos blogs investigados busca ensinar as mais diferentes teorias, métodos e atividades, sem se preocupar com a necessidade de uma coerência interna, mas expondo-se, ao mesmo tempo, a todas as leituras e reações possíveis diante do que é postado. Finalmente, a tecnologia da formação docente acionada nos blogs investigados incorpora e divulga as mais diferentes informações, disponibilizando uma grande variedade de materiais que as professoras-alfabetizadoras-blogueiras consideram "bem-feitos", "adequados", "eficientes", "bons" e importantes de serem divulgados e ensinados para professoras-alfabetizadoras que sentem dificuldades em sua tarefa de alfabetizar. Isto não significa que a qualidade desses materiais esteja garantida nem que o/a professor/a alfabetizador/a refletirá sobre o que está postando/publicando em seu blog, mas demonstra que os blogs sobre alfabetização são um espaço importante de produção curricular para essas docentes e que precisa ser estudado, analisado e investigado por novas pesquisas.

\section{REFERÊNCIAS}

AZEVEDO, Ana Lúcia de Faria e et al. A formação e a condição docente num contexto de complexidade e diversidade. In: DINIZ, Margareth; NUNES, Célia (Org.). Professor/a: profissão, condição e formação. Brasília: Liber Livro, 2013.

BRASIL, Secretaria de Educação Fundamental. Parâmetros Curriculares Nacionais: língua portuguesa. Brasília, 1997.

BROUGÈRE, Gilles. Jogo e a Educação. Porto Alegre: Artes Médicas, 1998. 
CALDEIRA, Maria Carolina da Silva. Dispositivo da Infantilidade no currículo do $1^{\circ}$ ano do ensino fundamental: conflitos entre a antecipação e a demarcação do/a infantil. 2016. 263f. Tese (Doutorado em Educação). Universidade Federal de Minas Gerais, Faculdade de Educação. Belo Horizonte, 2016.

CARVALHO, Marlene. Alfabetizar e letrar: um diálogo entre a teoria e a prática. 7. ed. Petrópolis, RJ: Vozes, 2010.

DOMINGUEZ, Daniel et al. Etnografía virtual. Fórum: Qualitative Social Research, v. 8, n. 3, p. 1-3, 2007. Disponível em: http://www.qualitative-

research.net/index.php/fqs/article/viewArticle/274/603. Acesso em: 13 jan. 2017.

ELKONIN, Danilo Borisovich. Psicologia do jogo. São Paulo: Martins Fontes, 1998.

FISCHER, Rosa Maria Bueno. Foucault e a análise do discurso em educação. Cadernos de Pesquisa, n. 114, p. 197-223, nov. 2001.

FONSECA, Márcio Alves da. A preocupação com o sujeito e o poder. In: FONSECA, Márcio Alves da (Org.). Michel Foucault e a constituição do sujeito. São Paulo: Educ, 1995. P. 21-37.

FOUCAULT, Michel. Verdade e subjetividade. Revista de Comunicação e Linguagem. Lisboa, n. 1, p. 203-223, 1993.

FOUCAULT, Michel. O sujeito e o poder. In: DREYFUS, Hubert; RABINOW, Paul (Org.). Michel Foucault: uma trajetória filosófica para além do estruturalismo e da hermenêutica. Rio de Janeiro: Forense Universitária, 1995.

FORTUNA, Tânia Ramos; VIEIRA, Lisiane Alves. Quem quer brincar na universidade? In: MOLL, Jaqueline (Org.). Múltiplos alfabetismos: diálogos com a escola pública na formação de professores. Porto Alegre: Editora da UFRGS, 2005.

FRADE, Isabel Cristina Alves da Silva. Métodos e Didáticas de Alfabetização: história, características e modos de fazer de professores: caderno do professor. Belo Horizonte: Ceale/FaE, UFMG, 2005.

GIROUX, Henry A. Praticando estudos culturais nas faculdades de educação. In: SILVA, Tomaz Tadeu da; MOREIRA, Antonio Flávio (Org.). Territórios contestados: o currículo e os novos mapas culturais. 5. ed. Petrópolis, RJ: Vozes, 1995.

JENKINS, Henry; GREEN, Joshua; FORD, Sam. Cultura da conexão: criando valor e significado por meio da mídia propagável. São Paulo: Aleph, 2014.

LEITE, Elvira; ORVALHO, Luísa. O professor aprendiz: criar o futuro. Programa Europeu PETRA II, Ação II. Ministério da Educação, Departamento do Ensino Secundário. Lisboa: Tradução portuguesa, 1995. 
LÉVY, Pierre. Cibercultura. São Paulo: Ed. 34, 1999.

LÉVY, Pierre. A inteligência coletiva: por uma antropologia do ciberespaço. 10. ed. São Paulo: Edições Loyola, 2015.

LIMA, José Milton. O jogo como recurso pedagógico no contexto educacional. São Paulo: Cultura, 2008.

MEYER, Dagmar Estermann; PARAÍSO, Marlucy Alves. Metodologias de pesquisas póscríticas ou sobre como fazemos nossas investigações. In: MEYER, Dagmar Estermann; PARAÍSO, Marlucy Alves (Org.). Metodologias de pesquisa pós-críticas em educação. Belo Horizonte: Mazza Edições, 2012.

MORAIS, Artur Gomes de. Concepções e Metodologias de Alfabetização: por que é preciso ir além da discussão sobre velhos "métodos"? Trabalho apresentado no XIII ENDIPE sob o título "Discursos recentes sobre alfabetização no Brasil", 2006. Disponível em: http://portal.mec.gov.br/seb/arquivos/pdf/Ensfund/alf_moarisconcpmetodalf.pdf. Acesso em: 04 jul. 2016.

MOREIRA, Antônio Flávio Barbosa. Currículos e Programas no Brasil. Campinas: Papirus, 1990.

MOREIRA, Antônio Flávio Barbosa. Os parâmetros curriculares em questão. Educação e Realidade, v. 21, n. 1, p. 9-22, jan./jun. 1996.

MORTATTI, Maria Rosário Longo. História dos métodos de alfabetização no Brasil. Conferência proferida durante o Seminário "Alfabetização e letramento em debate", promovido pelo Departamento de Políticas de Educação Infantil e Ensino Fundamental da Secretaria de Educação Básica do Ministério da Educação, realizado em Brasília, em 27 abr. 2006. Disponível em: http://portal.mec.gov.br/seb/arquivos/pdf/Ensfund/alf_ mortattihisttextalfbbr.pdf. Acesso em: 06 jul. 2016.

PARAÍSO, Marlucy Alves. Política da subjetividade docente no currículo da mídia educativa brasileira. Educação e Sociedade, Campinas, v. 27, n. 94, p. 91-115, jan./abr. 2006.

PARAÍSO, Marlucy Alves. Currículo e mídia educativa brasileira: poder, saber e subjetivação. Chapecó: Argos, 2007.

PARAÍSO, Marlucy Alves. Pesquisas sobre currículos e culturas: temas, embates, problemas e possibilidades. Curitiba: CRV, 2010a.

PARAÍSO, Marlucy Alves. O currículo entre a busca por "bom desempenho" e a garantia das diferenças. In: DALBEN, Ângela et al. (Org.). Convergências e tensões no campo da formação e do trabalho docente. Belo Horizonte: Autêntica, 2010b. P. 132-152. 
PEREIRA, Cleuzira Custódia et al. Alfabetização: métodos e algumas reflexões. Artigo apresentado à Faculdade de Caldas Novas - UNICALDAS como exigência para fins avaliativos da disciplina Fundamentos e Métodos da Alfabetização no $5^{\circ}$ período do curso de Pedagogia, 2013. Disponível em: http://www.unicaldas.edu.br/uploads/files/METODO_ALFABETIZACAO.pdf. Acesso em: 04 jul. 2016.

PIAGET, Jean William Fritz. A formação do símbolo na criança: imitação, jogo e sonho, imagem e representação. 2. ed. Rio de Janeiro: Zahar, 1975.

PINTO, Virginia Bentes; et al. "Netnografia": uma abordagem para estudos de usuários no ciberespaço. In: CONGRESSOS DE BIBLIOTECÁRIOS, ARQUIVISTAS E DOCUMENTALISTAS, n.9; 2007. Actas. [S.1.]: [s.n.], 2007. p. 1-10.

ROSE, Nikolas. Inventando nossos eus. In: SILVA, Tomaz Tadeu da (Org.). Nunca fomos humanos: nos rastros do sujeito. Belo Horizonte: Autêntica, 2001a.

ROSE, Nikolas. Como se deve fazer a história do eu?. Educação \& Realidade, n. 26, v. 1, p. 33-57, jan./jul., 2001b.

SANTOS, Lucíola Licínio; PARAISO, Marlucy Alves. O currículo como campo de luta. Presença Pedagógica. v. 2, n. 7, p. 33-39, jan./fev.1996.

SERRES, Michel. Novas Tecnologias e Sociedade Pedagógica: uma conversa com Michel Serres. Revista Interface - Comunicação, Saúde, Educação, p. 129-142, fev. 2000.

SERRES, Michel. Polegarzinha: uma nova forma de viver em harmonia, de pensar as instituições, de ser e de saber. Rio de Janeiro: Bertrand Brasil, 2013.

SILVA, Tomaz Tadeu da. Documentos de identidade: uma introdução às teorias do currículo. 3. ed. Belo Horizonte: Autêntica, 2013.

SOARES, Magda. A reinvenção da alfabetização. Presença Pedagógica, v. 9, n. 52, jul./ago. 2003.

SOARES, Magda. Letramento e Alfabetização: as muitas facetas. Revista Brasileira de Educação, n. 25, p. 5-17, jan./abr. 2004.

SOARES, Magda. Letramento: um tema em três gêneros. 3. ed. Belo Horizonte: Autêntica, 2012.

SOARES, Magda. Alfabetização: a questão dos métodos. São Paulo: Contexto, 2016.

VEIGA-NETO, Alfredo. Olhares... In: COSTA, Marisa Vorraber (Org.). Caminhos investigativos I: novos olhares na pesquisa em educação. 3. ed. Rio de Janeiro: Lamparina, 2007. P. 23-38. 
WEISZ, Telma. O diálogo entre o ensino e a aprendizagem. São Paulo: Ática, 1999.

\section{NOTAS}

${ }^{\mathrm{i}}$ Para o acesso à lista completa dos blogs investigados, acesse o trabalho completo no site da biblioteca da FaE/UFMG, disponível em: <http://www.bibliotecadigital.ufmg.br/dspace/handle/1843/BUOS-AQRGG5>. Acesso em: 12 jun. 2018.

ii As técnicas de dominação são aquelas "exercidas sobre os outros", podendo funcionar tanto pela "violência" quanto pelo "poder" (VEIGA-NETO, 2007, p. 954).

iii Já as "tecnologias do eu” ou "técnicas de si” (VEIGA-NETO, 2007, p. 954) são aquelas que envolvem algum nível de exercício ou de investimento do indivíduo em/sobre si mesmo.

iv O termo "netnografia" (assim como termos designados por "etnografia digital", "etnografia on-line", "etnografia na internet", "etnografia conectiva", "etnografia da rede" e "ciberetnografia") tem sido utilizado para denominar uma forma específica da etnografia, aquela realizada com "os grupos online" (DOMINGUEZ et al. 2007, p. 4). Os termos "netnografia" ou "etnografia virtual" surgiram para demarcar um tipo de pesquisa que "estuda as culturas e comunidades on-line emergentes, mediadas por computador, ou comunicações baseadas na Internet" (PINTO et al. 2007, p. 5).

"Disponível em:

<http://canttinhodaprofeadri.blogspot.com.br/search/label/\%/E2\%99\%A5\%20Alfabetiza\%C3A7\%C3\%A3o>.

Acesso em: 04 jul. 2016.

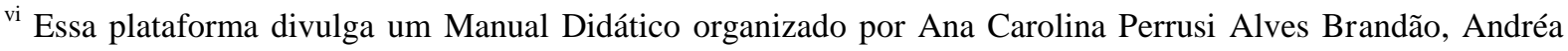
Tereza Bito Ferreira, Eliana Borges Correia de Albuquerque e Telma Ferraz Leal (Org.), intitulado "Jogos de Alfabetização" e disponibilizado no site do MEC no seguinte endereço eletrônico: <http://www.plataformadoletramento.org.br/arquivo_upload/2014-02/20140210152238-

mec_ufpe_manual_de_jogos_didaticos_revisado.pdf>. Acesso em: 04 jul. 2016.

vii Disponível em: <http://pacto.mec.gov.br/2012-09-19-19-09-11>. Acesso em: 04 jul. 2016.

viii Disponível em: <http://portaldoprofessor.mec.gov.br/fichaTecnicaAula.html?aula=48776>. Acesso em: 04 jul. 2016.

ix Disponível em: <http://priscilapiassi.blogspot.com.br/2013/09/manual-de-jogos-alfabetizacao.html>. Acesso em: 08 dez. 2016.

x A cartilha surgiu no Brasil no final da década de 1980 e baseava-se nos "métodos de marcha sintética (de soletração, fônico e de silabação) e circulou em várias províncias/estados do país e por muitas décadas" (MORTATTI, 2006, p. 5).

${ }^{x i}$ A teoria da Psicogênese da Língua Escrita, construída por Emilia Ferreiro e Ana Teberosky no final da década de 1970 e início da década de 1980, foi a que primeiro deslocou o foco "do ensino para a aprendizagem", partindo "não de como se deve ensinar e sim de como de fato se aprende" (WEISZ, 1999, p. ix).

xii Muitos estudiosos e especialistas têm pensando a respeito do tema. A seguir, encontram-se 12 livros que falam sobre alfabetização destinados à professores/as, os quais foram escolhidos para serem publicados pelas editoras: Alfabetização, leitura do mundo, leitura da palavra (Paulo Freire); Alfabetização e Letramento (Magda Soares); Reflexões sobre a alfabetização (Emilia Ferreiro); Alfabetização: um processo em construção (Maria de Fátima Russo); Coleção Didática da alfabetização (Esther P. Grossi); Além da alfabetização (Ana Theberosky); Alfabetização em três propostas (Ana Cecília Onativia); Psicanálise da Alfabetização (Bruno Bettelhein); Alfabetização possível (Jaqueline Moll); A construção social da alfabetização (Jenny Cook-Gumperz); Fundamentos e Metodologias da Alfabetização (Gilda Rizzo); Construindo a Alfabetização (Vilma Mello Biscolla). Disponível em: <http://blog.estantevirtual.com.br/2011/09/08/no-dia-internacional-da-alfabetizacao12-livros-sobre-o-assunto/>. Acesso em: 06 jul. 2016. 
xiii O currículo oficial é aquilo que "foi planejado oficialmente para ser trabalhado nas diferentes disciplinas e séries de um curso. É o que consta na Proposta Curricular do Estado, nas Propostas Curriculares das Secretarias de Educação ou nos livros didáticos elaborados a partir destas" (SANTOS; PARAÍSO, 1996, p. 84).

${ }^{\text {xiv }}$ Disponíveis em: <https://jucienebertoldo.wordpress.com/publicacoes/>; $<$ http://professoravivianferreira.blogspot.com.br/search/label/Referencial\%20Curricular>; <http://ensinar-aprender.com.br/2009/12/referencial-curricular.html>. Acesso em: 15 abr. 2016.

${ }^{x v}$ Disponível em: <http://professoravivianferreira.blogspot.com.br/>. Acesso em: 05 jul. 2016.

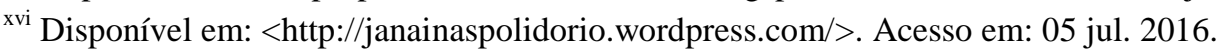

xvii Disponível em: <http://professoravivianferreira.blogspot.com.br/>. Acesso em: 05 jul. 2016.

xviii Disponível em: <http://janainaspolidorio.wordpress.com/>. Acesso em: 05 jul. 2016.

${ }^{x i x}$ Disponível em: <http://diariodaprofaglauce.blogspot.com.br/>. Acesso em: 05 jul. 2016.

${ }^{x x}$ Disponível em: <http://saberesefazeresnaeducacao.blogspot.com.br/>. Acesso em: 04 jul. 2016.

xxi Disponível em: <http://baudaalfabetizacao.blogspot.com.br/>. Acesso em: 04 jul. 2016.

xxii Disponível em: <http://renata.piraju.tur.be/?page_id=19>. Acesso em: 04 jul. 2016.

xxiii Disponível em: <http://professorajanainaspolidorio.wordpress.com/>. Acesso em: 04 jul. 2016.

${ }^{x x i v}$ Disponível em: <http://diversosblogseducacionais.blogspot.com.br/>. Acesso em: 04 jul. 2016.

${ }^{x x v}$ Disponível em: <http://www.rioeduca.net/blogViews.php?id=1750>. Acesso em: 18 jul. 2016.

xxvi Disponível em: <http://www.atividades-escolares.com/search/label/COMO\%20ALFABETIZAR>. Acesso em: 18 jul. 2016.

xxvii Disponível em:

$<$ http://alfabetizacaocefaproponteselacerda.blogspot.com.br/search/label/M\%C3\%A9todo\%20Alfab\%C3\%A9ti co>. Acesso em: 18 jul. 2016.

xxviii Disponível em: <http://www.mundinhodacrianca.net/2009/10/metodos-de-alfabetizacao-quais-sao-e.html>. Acesso em: 05 jun. 2018.

${ }^{x x i x}$ Isabel Frade (2005, p. 49), por exemplo, critica a "adoção rígida" de uma perspectiva, o trabalho que visa apenas à "codificação/decodificação", bem como a crença de que todos os alunos se apropriam do sistema de escrita "sempre da mesma forma e no mesmo ritmo".

xxx Tais autores preferem o termo "circulação" ao termo "distribuição", pois sinaliza um "modelo mais participativo", em que não há mais um público passivo e recebedor de informações, mas várias pessoas ou grupos que "estão moldando, compartilhando, reconfigurando e remixando conteúdos" (JENKINS; FORD; GREEN, 2014, p. 24).

\section{Sobre as Autoras}

${ }^{1}$ Gabriela Silveira Meireles - Doutora pela Faculdade de Educação pela Universidade Federal de Minas Gerais - E-mail: gabrielasilveirameireles@gmail.com - ORCID: https://orcid.org/0000-0002$\underline{9712-5488}$

2 Marlucy Alves Paraíso - Professora Titular da Faculdade de Educação da Universidade Federal de Minas Gerais - E-mail: marlucyparaiso@gmail.com - ORCID: http://orcid.org/0000-0002-3542-4650 